Article

\title{
The Half-Size ABC Transporter FOLDED PETALS 2/ABCG13 Is Involved in Petal Elongation through Narrow Spaces in Arabidopsis thaliana Floral Buds
}

\section{Seiji Takeda ${ }^{1,2, \dagger, *}$, Akira Iwasaki ${ }^{3,4, \dagger}$, Kiyoshi Tatematsu ${ }^{3}$ and Kiyotaka Okada ${ }^{3, \star}$}

1 Graduate School of Life and Environmental Sciences, Kyoto Prefectural University, Sakyo-ku, Kyoto 606-8522, Japan

2 Biotechnology Research Department, Kyoto Prefectural Agriculture Forestry and Fisheries Technology Center, Seika, Kyoto 619-0244, Japan

3 Laboratory of Plant Organ Development, National Institute for Basic Biology, Okazaki, Aichi 444-8585, Japan; E-Mails: iwaaki0123@gmail.com (A.I.); ktatem@nibb.ac.jp (K.T.); kiyo@nins.jp (K.O.)

4 Department of Botany, Graduate School of Science, Kyoto University, Kyoto 606-8502, Japan

$\dagger$ These authors contributed equally to this work.

* Present address: National Institute of Natural Sciences, Tokyo 105-0001, Japan.

* Author to whom correspondence should be addressed; E-Mail: seijitakeda@kpu.ac.jp; Tel.: +81-774-93-3526; Fax: +81-774-93-35282.

Received: 20 June 2014; in revised form: 19 July 2014 / Accepted: 11 August 2014 / Published: 15 August 2014

Abstract: Flowers are vital for attracting pollinators to plants and in horticulture for humans. Petal morphogenesis is a central process of floral development. Petal development can be divided into three main processes: the establishment of organ identity in a concentric pattern, primordia initiation at fixed positions within a whorl, and morphogenesis, which includes petal elongation through the narrow spaces within the bud. Here, we show that the FOLDED PETALS 2 (FOP2) gene, encoding a member of the half-size ATP binding cassette $(\mathrm{ABC})$ transporter family $\mathrm{ABCG} 13$, is involved in straight elongation of petals in Arabidopsis thaliana. In fop 2 mutants, flowers open with folded petals, instead of straight-elongated ones found in the wild type. The epicuticular nanoridge structures are absent in many abaxial epidermal cells of fop 2 petals, and surgical or genetic generation of space in young fop 2 buds restores the straight elongation of petals, suggesting that the 
physical contact of sepals and petals causes the petal folding. Similar petal folding has been reported in the fop 1 mutant, and the petals of fop 2 fop 1 double mutants resemble those of both the fop 1 and fop 2 single mutants, although the epidermal structure and permeability of the petal surface is more affected in fop 2 . Our results suggest that synthesis and transport of cutin or wax in growing petals play an important role for their smooth elongation through the narrow spaces of floral buds.

Keywords: Arabidopsis thaliana; floral organs; folded petals; petal elongation; ABC transporter; ABCG13

\section{Introduction}

Petals have evolved to have various colors, shapes, and fragrances, and, thus, their morphogenesis is critical in attracting pollinators for plants and in horticulture for humans. Flowers usually develop three other distinct organs, each with a specialized function. In Arabidopsis thaliana, the floral primordia initiate at the flanks of the shoot apical meristem as floral meristems, subsequently sepals arise, first in the outermost concentric region, and cover the floral meristem, protecting the other inner organs as they develop. Gynoecia and stamens are reproductive organs: gynoecia arise in the center of the flower, surrounded by a number of stamens.

Petal development can be divided into three main processes. First is the identity determination, described by the floral ABCE model, which explains that the organ identity is established in a concentric pattern by combined functions of the floral homeotic genes [1-4]. In addition to these main factors, miRNA172 and other transcription factors such as AINTEGUMENTA, LEUNIG, SEUSS, RABBIT EARS (RBE), and STERILE APETALA, are involved in fine-tuning of expression of the floral ABCE genes in Arabidopsis thaliana [5-13]. The second process is primordia initiation at fixed positions within each concentric region or whorl. In many flowering plants, such as Brassicaceae, petals initiate at the inner site of the sepal boundary region, thus, the number of petals and sepals is the same. Usually, positions where floral organ primordia arise within a whorl are fixed relative to the adaxial-abaxial and lateral axes of floral meristem. Although the molecular mechanism for determination of initiation position remains unclear, some genes that are expressed in a position-dependent manner, such as PETAL LOSS (sepal boundary), RBE (petal primordia), ROXY1 (young floral organ primordia), and UNUSUAL FLORAL ORGANS (which changes its expression pattern as a flower develops), seem to be involved in position-dependent primordia development [14-18]. The third process is petal morphogenesis after initiation, which is regulated by cell division, cell expansion, and endoreduplication, regulated by JAGGED, BIGPETALP, and FRILL genes [19-26].

Previously we showed a mutant, folded petals 1 (fopl), which in Arabidopsis thaliana has a defect in the petal elongation process [27]. In the wild type, petals elongate straight through the narrow space between sepals and anthers in the floral bud. In fop 1, petals become stuck in the bud during elongation, resulting in the formation of folded petals in the open flower. FOPl encodes a member of the WAX ESTER SYNTHASE/DIACYLGLYCEROL ACYLTRANSFERASE (WS/DGAT) family WSD11 
and is expressed in growing petals, suggesting that FOP1 is involved in production of fatty acids that makes petal elongation smooth in narrow space in floral buds, and that petal morphogenesis is affected by the physical interaction of floral organs.

Here, we describe the characterization of another mutant, folded petals 2 (fop 2), which has a similar petal folding phenotype to fop1. Our results suggest that FOP2 regulates petal elongation at distinct stages of the same pathway of FOP1, and that export of cutin and/or wax to the surface of the petal epidermis is important for petal morphogenesis.

\section{Results and Discussion}

\subsection{Folded Petals Phenotype in the Fop2 Mutant}

During a screen for floral organ defective mutants in Arabidopsis thaliana, we found a couple of mutants defective in the petal elongation process. Their flowers open with folded petals instead of wild-type straight-elongated ones, so we named these mutants folded petals (fop). One of these mutants, named fop 2-1, produces flowers with folded petals with the shape of ' $\mathrm{N}$ ' letter, instead of wild-type straight elongated petals (Figure 1a,b). About half of petals were unfolded (Table 1), but most of them were wrinkled, suggesting the trace of physical friction during petal elongation in flower buds (Supplementary Figure S1). After identification of the FOP2 gene by map-based cloning (see below) we analyzed a SALK T-DNA insertion line (SALK_046735), which we named fop2-2, and found that this line showed the weaker but similar petal defects to fop 2-1 (Figures 1c and S1). Since the fop1 mutant showed similar petal defects [27], we examined the relationship between fop 1 and fop 2 by generating the double mutant. Flowers in the fop 2-1 fop 1-1 double mutant showed similar petal folding to single mutants, and this phenotype was not enhanced in the double mutant as compared to the fop 2 single mutant (Figure 1d and Table 1), suggesting that FOP1 and FOP2 are involved in the same pathway of petal elongation.

To examine the petal defects in more detail, we analyzed the structure of the petal epidermis using scanning electron microscopy. In wild-type, petal epidermal cells are conical-shaped and epicuticular nanoridges cover their surface (Figure 1e). In fop2-1, many epidermal cells are flattened and lack the epicuticular nanoridges at their tip (Figure 1f). This defect was also observed on the fopl petal epidermis, suggesting that fop 2 petals make physical contact with sepals, as do the fop 1 petals [27]. In several regions on the fop 2-1 petal surface, a number of long cells lacking epicuticular nanoridges seemed to be aggregated at one site (Figure 1f). This phenotype was not detected in the wild type or fop1, suggesting that FOP1 and FOP2 have different roles in determining the petal epidermal character.

Some other mutants showing the petal-folding phenotype are sensitive to dye immersion due to the lowered repellency of petal surface [28-30]. We examined the surface repellency of fop 2 by immersing petals in toluidine blue solution [31]. Petals from wild-type flowers were not stained, but the fop 2 petals were stained in the blade region (Figure 1g,h). Interestingly, the fopl petals were not stained except for the claw edge (Figure1g,h), probably because this region contacts to the sepal surface and thus has reduced repellency [27]. These results indicate that the petal repellency is lower in fop 2 than in fop 1, suggesting that FOP2 and FOP1 have distinct functions. 
Together, our results suggest that $F O P 1$ and $F O P 2$ regulate petal elongation in two distinct stages of the same pathway.

Figure 1. (a) Wild-type (WS) flower with straight petals; (b) fop2-1 flower with folded petals; (c) fop 2-2/SALK_046735 flower with folded petals; (d) fop2-1 fop 1-1 flower; (e,f) Scanning electron micrographs of wild-type (e) and fop2-1 (f) petals; (g,h) Toluidine blue-stained flowers (g) and petals (h) of wild-type (WS), fop1-1, and fop2-1. Arrowhead indicates the edge staining of the fop $1-1$ petal. Bars: a, b, c, d, g, h, $1 \mathrm{~mm}$; e, f, $20 \mu \mathrm{m}$.
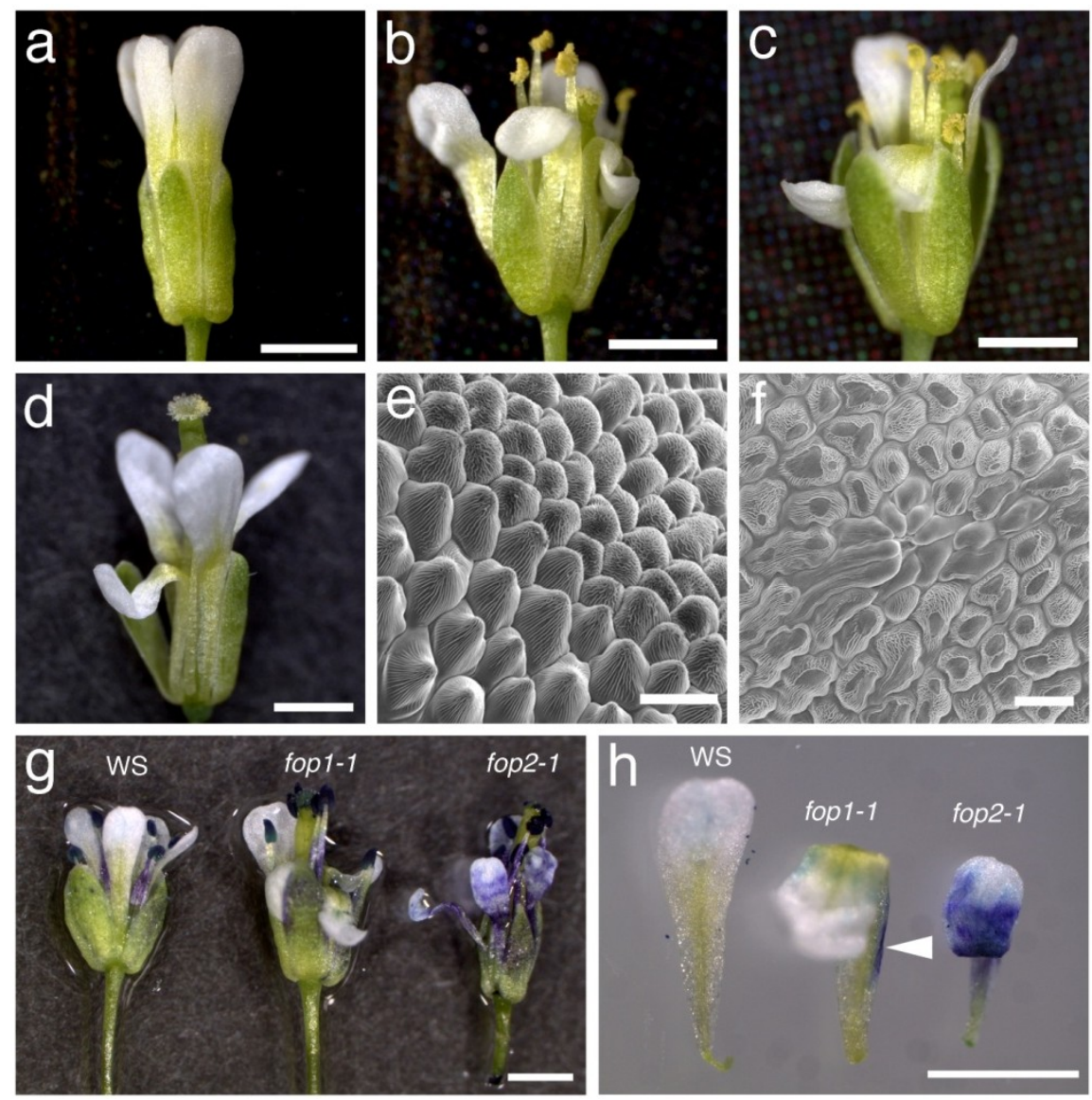

Table 1. Floral organ number of the fop $2-1$ single and double mutants.

\begin{tabular}{cccccc}
\hline \multirow{2}{*}{ Genotype } & \multirow{2}{*}{ Sepal } & \multicolumn{2}{c}{ Petal } & \multirow{2}{*}{ Stamen } & \multirow{2}{*}{ Carpel } \\
\cline { 3 - 4 } & & Unfolded & Folded & & \\
\hline WS & $4 \pm 0$ & $4 \pm 0$ & $0 \pm 0$ & $5.55 \pm 0.60$ & $2 \pm 0$ \\
fop2-1 & $4 \pm 0$ & $2.15 \pm 0.75$ & $1.85 \pm 0.75^{\text {a }}$ & $5.90 \pm 0.45$ & $2 \pm 0$ \\
fop2-1 fop 1-1 & $4 \pm 0$ & $1.85 \pm 1.27$ & $2.15 \pm 1.27^{\text {a }}$ & $5.75 \pm 0.44$ & $2 \pm 0$ \\
prs-1 fop2-1 & $4 \pm 0$ & $3.95 \pm 0.22$ & $0.55 \pm 0.22$ & $5.95 \pm 0.22$ & $2 \pm 0$ \\
\hline
\end{tabular}

Twenty flowers were examined in each line. Numbers indicate the average organ number $\pm \mathrm{SD} .{ }^{\mathrm{a}}$ No significant difference each other (Student's $t$-test, $p>0.05$ ).

\subsection{Surgical and Genetic Generation of Space in a Floral Bud Restored Petal Elongation}

We hypothesized that petal folding of fop 2 is caused by the narrow space in the floral buds, as shown in the fop 1 mutant [27]. To elucidate this, we removed the sepals from the fop 2-1 floral buds 
prior to flower opening (Figure 2a, around floral stage 10 to 12 as defined in [32]). After three days, we found that all examined flowers restored the straight elongation of petals (Figures $2 \mathrm{~b}$ and S2). We also examined the fop 1 fop 2 double mutant in the same way, with similar results (Figure S2). Next, we investigated the pressed flower-1 (prs-1) fop2-1 double mutant. prs-1 is defective in the development of lateral domains of organs, and raises flowers with narrower sepals, resulting in "open" floral buds [33]. The floral buds of prs-1 fop 2-1 double mutants generate space in these open buds, compared to the closed buds in fop2-1 (Figure $2 \mathrm{~d}$ and inset), and almost all petals elongated straight in the double mutant (Figure $2 \mathrm{c}$ and Table 1). These results indicate that surgical or genetic generation of space in a floral bud restores the straight elongation of fop 2 petals. Taken together, the data suggest that the fop 2 lacks lubricant-like materials that allow petals to elongate smoothly in the narrow space in a floral bud.

We also investigated flowers of the ap3-5 fop 2-1 double mutant, whose petals were transformed to sepals, and found that the second whorl organ elongated normally (Figure 2e). This suggests the possibility that FOP2 function is restricted to the organs with petal identity, and that sepals may have other ABCG transporters involved in cuticle wax deposition.

Figure 2. (a) fop2-1 flower whose sepal is removed at stage 11. Petals are indicated by white dotted line. p, petal; st, stamen; g, gynoecium; (b) Same flower as (a) after three days. Note the straight elongation of petals; (c) prs-1 fop 2-1 flower; (d) Inflorescence of prs-1 fop 2-1. Inset is inflorescence of fop 2-1; (e) ap3-5 fop2-1 flower. Bars: $1 \mathrm{~mm}$.
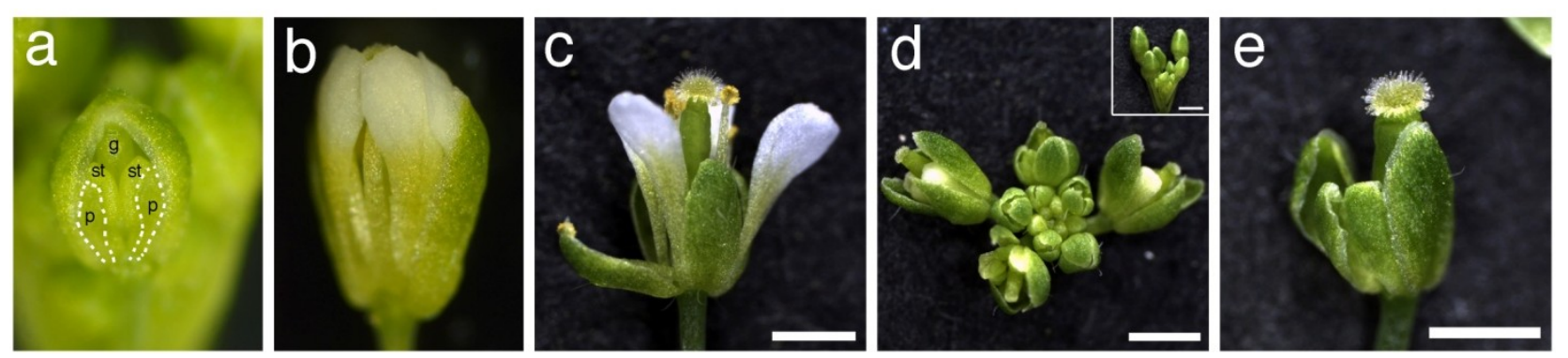

\subsection{Mapping and Characterization of the FOP2 Gene}

To characterize the molecular function of FOP2, we mapped the FOP2 gene on chromosome 1 and identified a mutation in At1g51460 (Figure 3). The fop2-1 mutation is a nucleotide substitution of cytosine to thymine in the third exon, causing the change of a glutamine at the position of 194 to a premature stop in the amino acid residues (Figures 3b and S3). We analyzed the SALK_046735 line, in which the T-DNA is inserted in the 4th exon of At1g51460. Sequencing of border regions revealed that the T-DNA caused a 15 bp deletion in the 4th exon (Figures $3 \mathrm{~b}$ and S3). This line showed the same petal-folding phenotype as shown above (Figure 1c).

FOP2 encodes a member of the ATP-binding cassette (ABC) transporter family protein, ABCG13, which has been already reported by Panikashvili et al. [34]. They showed the folded-petal phenotype in SALK_046735 (abcg13) and RNAi-based knockdown lines, and several species of cutin monomers were reduced in these flowers. We examined the FOP2 expression pattern by generating FOP 2 genomic: $G U S$ translational fusion lines, and found that FOP2 was expressed in petals and ovule integuments, as well as the L1 layer of peduncles (Figure S4). The expression pattern is largely consistent with promoter:GUS transcriptional fusion results from Panikashvili et al. [34]. 
Figure 3. (a) Diagram of $F O P 2$ mapping. DNA markers and number of recombinants are indicated; (b) Genomic structure of the FOP2 gene. Point mutation of fop2-1 and T-DNA insertion, which causes the 15 bp deletion, in fop2-2/SALK_046735 are indicated. LB, left border of T-DNA. See Figure S2 for FOP2 genomic sequence.

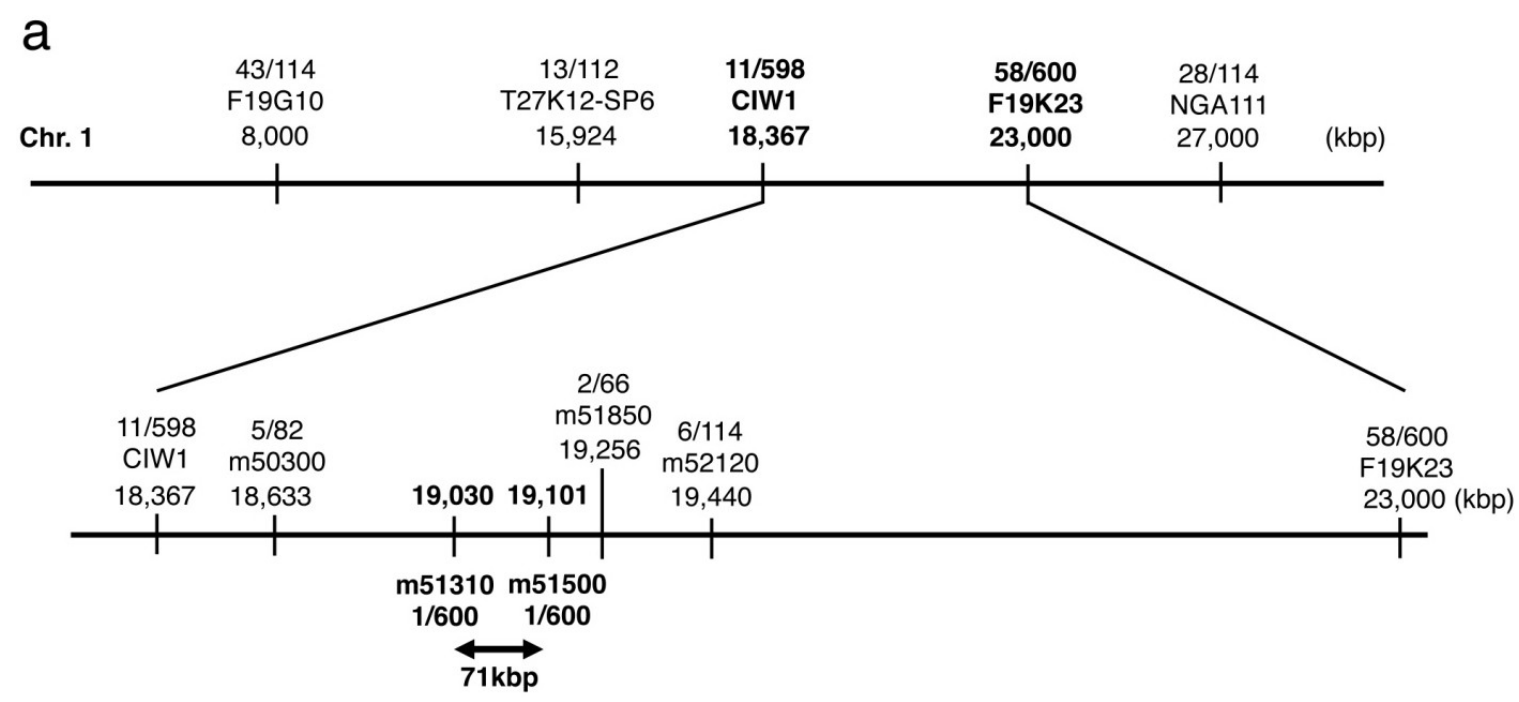

b

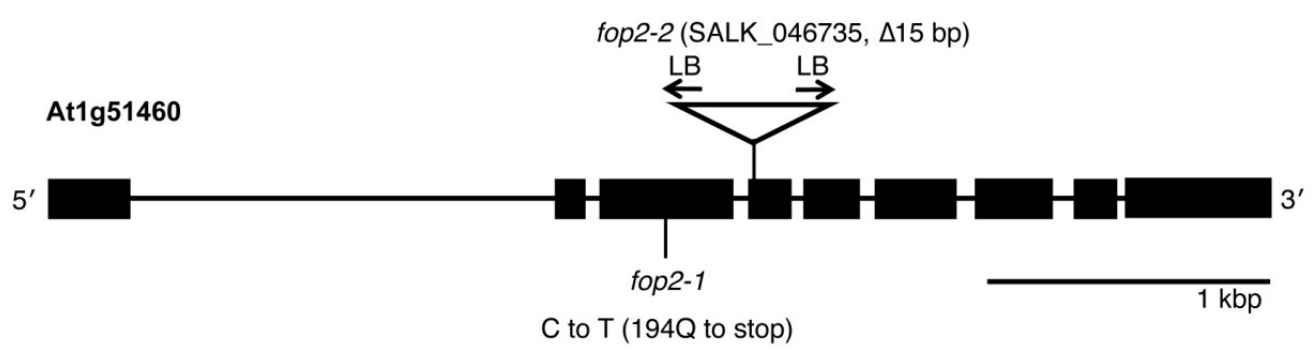

\subsection{Molecular Function of FOP2 in Petal Elongation Process}

FOP2/ABCG13 belongs to the WHITE-BROWN COMPLEX (WBC) subfamily, members of which are half-transporter proteins [35,36]. ABCG11/AtWBC11/DSO and ABCG12/CER5 in the same subfamily function as homodimers or heterodimers on plasma membranes in planta [37], thus, FOP2/ABCG13 would interact with itself or the other WBC members on plasma membrane of petal epidermal cells. Our results from petal epidermis characterization, petal surface repellency tests and the phenotype of the double mutant suggest that production and deposition of the lubricant-like substrates, mediated by FOP1/WSD11 and FOP2/ABCG13, respectively, are a critical process for smooth elongation of petals in the narrow space in floral buds. Since the known half-size ABCG transporters are involved in secretion of both cutin and wax [34,38-42], it is possible that FOP2 transports the FOP1 products to the petal surface. Interestingly FOP1/WSD11 is located to the plasma membrane, suggesting that FOP2 and FOP1 may co-localize on the plasma membrane of petal epidermal cells. Identification of substrates and products of FOP1 and FOP2 will unveil the molecular mechanism of petal elongation in detail. 


\section{Experimental Section}

\subsection{Plant Lines and Growth Conditions}

The Wassilewskija (WS), Columbia (Col), and Landsberg erecta (Ler) ecotypes of Arabidopsis thaliana were used as wild-types. The fop2-1 mutant was isolated from an M2 population of ethyl methanesulfonate-mutagenized long hypocotyl 5 (hy5) in which the HY5 genomic fragment was transformed [43]. fop2-2/SALK_046735, a T-DNA insertion mutant, was obtained from the SIGnAL Website [44] and the Arabidopsis Biological Resource Center [45]. Plants were grown on MS media or vermiculite in small pots under long-day conditions (16 h light and $8 \mathrm{~h}$ dark) with white light at $22{ }^{\circ} \mathrm{C}$ to $24^{\circ} \mathrm{C}$.

\subsection{Histology and Microscopes}

Images were captured using an S8AP0 binocular microscope or DM2500 light microscope equipped with an EC3 digital camera system (Leica, Wetzlar, Germany). For scanning microscopy, samples were directly observed with JSM-5800 (JEOL). For toluidine blue staining, flowers were immersed in TB solution ( $0.05 \%$ toluidine blue (w/v, Waldeck, Münster, Germany) and $0.01 \%$ Tween 20 (v/v)) for 5 min and washed in water. At least fifteen (WS and fop 2-1) and five (fop 1-1) flowers were examined, respectively.

\subsection{Cloning and Expression Analysis of the FOP2 Gene}

F2 plants generated by crossing the fop 2-1 with Col and Ler were used for mapping. DNA marker information was obtained from The Arabidopsis Information Resource [46] and generated using polymorphisms between ecotypes. For genomic-GUS translational fusion, we fused the $5.7 \mathrm{~kb}$ genomic fragments including FOP2 5'-promoter and coding regions (without stop codon), $\beta$-glucuronidase (GUS), and $1.7 \mathrm{~kb} 3$ ' region, and cloned into the pGWB1-NB1 binary vector, and transformed to plants by a vacuum infiltration procedure with the Agrobacterium strain ASE1.

\section{Conclusions}

Our results suggest that a half-size ABC transporter, FOP2/ABCG13, is involved in the transport of the possible lubricant materials on the developing petal surface. It is possible that FOP2/ABCG13 transports the products of FOP1/WSD11 on the plasma membrane of petal epidermis, resulting in the smooth elongation of petals through the narrow spaces in floral buds. Main future works would be (1) examining the molecular relation between FOP2 and FOP1, including spatiotemporal expression/localization analysis in planta, and enzymatic activity assay; and (2) identifying the substances that function as lubricants during petal elongation. Our results propose the possibility to control the petal morphogenesis by modification of enzymes or transporters, or by exogenous application of these products/substances. 


\section{Acknowledgments}

We thank the Model Plant Research Facility, the NIBB Bioresource Center, the Salk Institute, and the Arabidopsis Biological Resource Center for providing materials, Rebecca Horn for critical reading of the manuscript, and lab members for helpful discussion. This work was supported by grants for young scientists from Kyoto Prefectural Public University Corporation to ST, a Grant-in-Aid for Scientific Research on Priority Areas (No. 19060004), and a Grant-in-Aid for Creative Scientific Research from the Japan Society for the Promotion of Science (No. 19GS0315) from the Ministry for Education, Culture, Sports, Science, and Technology (MEXT) of Japan to KO.

\section{Author Contributions}

S.T. and A.I. performed experiments, S.T. wrote papers, and K.T. and K.O. supervised this work.

\section{Conflicts of Interest}

The authors declare no conflict of interest.

\section{References}

1. Bowman, J.L.; Smyth, D.R.; Meyerowitz, E.M. Genes directing flower development in Arabidopsis. Plant Cell 1989, 1, 37-52.

2. Krizek, B.A.; Fletcher, J.C. Molecular mechanisms of flower development: An armchair guide. Nat. Rev. Genet. 2005, 6, 688-698.

3. Weigel, D.; Meyerowitz, E.M. The ABCs of floral homeotic genes. Cell 1994, 78, 203-209.

4. Theissen, G.; Saedler, H. Plant biology. Floral quartets. Nature 2001, 409, 469-471.

5. Byzova, M.V.; Franken, J.; Aarts, M.G.; de Almeida-Engler, J.; Engler, G.; Mariani, C.; van Lookeren Campagne, M.M.; Angenent, G.C. Arabidopsis STERILE APETALA, a multifunctional gene regulating inflorescence, flower, and ovule development. Genes Dev. 1999, $13,1002-1014$.

6. Conner, J.; Liu, Z. LEUNIG, a putative transcriptional corepressor that regulates AGAMOUS expression during flower development. Proc. Natl. Acad. Sci. USA 2000, 97, 12902-12907.

7. Franks, R.G.; Wang, C.; Levin, J.Z.; Liu, Z. SEUSS, a member of a novel family of plant regulatory proteins, represses floral homeotic gene expression with LEUNIG. Development 2002, 129, 253-263.

8. Grigorova, B.; Mara, C.; Hollender, C.; Sijacic, P.; Chen, X.; Liu, Z. LEUNIG and SEUSS co-repressors regulate miR172 expression in Arabidopsis flowers. Development 2011, 138, 2451-2456.

9. Krizek, B.A.; Lewis, M.W.; Fletcher, J.C. RABBIT EARS is a second-whorl repressor of AGAMOUS that maintains spatial boundaries in Arabidopsis flowers. Plant J. 2006, 45, 369-383.

10. Krizek, B.A.; Prost, V.; Macias, A. AINTEGUMENTA promotes petal identity and acts as a negative regulator of AGAMOUS. Plant Cell 2000, 12, 1357-1366.

11. Liu, Z.; Meyerowitz, E.M. LEUNIG regulates AGAMOUS expression in Arabidopsis flowers. Development 1995, 121, 975-991. 
12. Sridhar, V.V.; Surendrarao, A.; Gonzalez, D.; Conlan, R.S.; Liu, Z. Transcriptional repression of target genes by LEUNIG and SEUSS, two interacting regulatory proteins for Arabidopsis flower development. Proc. Natl. Acad. Sci. USA 2004, 101, 11494-11499.

13. Chen, X. A microRNA as a translational repressor of APETALA2 in Arabidopsis flower development. Science 2004, 303, 2022-2025.

14. Takeda, S.; Matsumoto, N.; Okada, K. RABBIT EARS, encoding a SUPERMAN-like zinc finger protein, regulates petal development in Arabidopsis thaliana. Development 2004, 131, 425-434.

15. Griffith, M.E.; da Silva Conceicao, A.; Smyth, D.R. PETAL LOSS gene regulates initiation and orientation of second whorl organs in the Arabidopsis flower. Development 1999, 126, 5635-5644.

16. Lee, I.; Wolfe, D.S.; Nilsson, O.; Weigel, D. A LEAFY co-regulator encoded by UNUSUAL FLORAL ORGANS. Curr. Biol. 1997, 7, 95-104.

17. Samach, A.; Klenz, J.E.; Kohalmi, S.E.; Risseeuw, E.; Haughn, G.W.; Crosby, W.L. The UNUSUAL FLORAL ORGANS gene of Arabidopsis thaliana is an F-box protein required for normal patterning and growth in the floral meristem. Plant J. 1999, 20, 433-445.

18. Xing, S.; Rosso, M.G.; Zachgo, S. ROXY1, a member of the plant glutaredoxin family, is required for petal development in Arabidopsis thaliana. Development 2005, 132, 1555-1565.

19. Schiessl, K.; Muino, J.M.; Sablowski, R. Arabidopsis JAGGED links floral organ patterning to tissue growth by repressing Kip-related cell cycle inhibitors. Proc. Natl. Acad. Sci. USA 2014, $111,2830-2835$.

20. Sauret-Gueto, S.; Schiessl, K.; Bangham, A.; Sablowski, R.; Coen, E. JAGGED controls Arabidopsis petal growth and shape by interacting with a divergent polarity field. PLoS Biol. 2013, 11, e1001550.

21. Dinneny, J.R.; Yadegari, R.; Fischer, R.L.; Yanofsky, M.F.; Weigel, D. The role of JAGGED in shaping lateral organs. Development 2004, 131, 1101-1110.

22. Ohno, C.K.; Reddy, G.V.; Heisler, M.G.; Meyerowitz, E.M. The Arabidopsis JAGGED gene encodes a zinc finger protein that promotes leaf tissue development. Development 2004, 131, 1111-1122.

23. Szecsi, J.; Joly, C.; Bordji, K.; Varaud, E.; Cock, J.M.; Dumas, C.; Bendahmane, M. BIGPETALp, a bHLH transcription factor is involved in the control of Arabidopsis petal size. EMBO J. 2006, 25, 3912-3920.

24. Varaud, E.; Brioudes, F.; Szecsi, J.; Leroux, J.; Brown, S.; Perrot-Rechenmann, C.; Bendahmane, M. AUXIN RESPONSE FACTOR8 regulates Arabidopsis petal growth by interacting with the bHLH transcription factor BIGPETALp. Plant Cell 2011, 23, 973-983.

25. Hase, Y.; Fujioka, S.; Yoshida, S.; Sun, G.; Umeda, M.; Tanaka, A. Ectopic endoreduplication caused by sterol alteration results in serrated petals in Arabidopsis. J. Exp. Bot. 2005, 56, 1263-1268.

26. Hase, Y.; Tanaka, A.; Baba, T.; Watanabe, H. FRL1 is required for petal and sepal development in Arabidopsis. Plant J. 2000, 24, 21-32.

27. Takeda, S.; Iwasaki, A.; Matsumoto, N.; Uemura, T.; Tatematsu, K.; Okada, K. Physical interaction of floral organs controls petal morphogenesis in Arabidopsis. Plant Physiol. 2013, $161,1242-1250$. 
28. Li-Beisson, Y.; Pollard, M.; Sauveplane, V.; Pinot, F.; Ohlrogge, J.; Beisson, F. Nanoridges that characterize the surface morphology of flowers require the synthesis of cutin polyester. Proc. Natl. Acad. Sci. USA 2009, 106, 22008-22013.

29. Panikashvili, D.; Shi, J.X.; Schreiber, L.; Aharoni, A. The Arabidopsis DCR encoding a soluble BAHD acyltransferase is required for cutin polyester formation and seed hydration properties. Plant Physiol. 2009, 151, 1773-1789.

30. Oshima, Y.; Shikata, M.; Koyama, T.; Ohtsubo, N.; Mitsuda, N.; Ohme-Takagi, M. MIXTA-like transcription factors and WAX INDUCER1/SHINE1 coordinately regulate cuticle development in Arabidopsis and Torenia fournieri. Plant Cell 2013, 25, 1609-1624.

31. Tanaka, T.; Tanaka, H.; Machida, C.; Watanabe, M.; Machida, Y. A new method for rapid visualization of defects in leaf cuticle reveals five intrinsic patterns of surface defects in Arabidopsis. Plant J. 2004, 37, 139-146.

32. Smyth, D.R.; Bowman, J.L.; Meyerowitz, E.M. Early flower development in Arabidopsis. Plant Cell 1990, 2, 755-767.

33. Matsumoto, N.; Okada, K. A homeobox gene, PRESSED FLOWER, regulates lateral axis-dependent development of Arabidopsis flowers. Genes Dev. 2001, 15, 3355-3364.

34. Panikashvili, D.; Shi, J.X.; Schreiber, L.; Aharoni, A. The Arabidopsis ABCG13 transporter is required for flower cuticle secretion and patterning of the petal epidermis. New Phytol. 2011, 190, 113-124.

35. Kang, J.; Park, J.; Choi, H.; Burla, B.; Kretzschmar, T.; Lee, Y.; Martinoia, E. Plant ABC Transporters. Arabidopsis Book 2011, 9, e0153.

36. Samuels, L.; Kunst, L.; Jetter, R. Sealing plant surfaces: Cuticular wax formation by epidermal cells. Annu. Rev. Plant Biol. 2008, 59, 683-707.

37. McFarlane, H.E.; Shin, J.J.; Bird, D.A.; Samuels, A.L. Arabidopsis ABCG transporters, which are required for export of diverse cuticular lipids, dimerize in different combinations. Plant Cell 2010, 22, 3066-3075.

38. Bird, D.; Beisson, F.; Brigham, A.; Shin, J.; Greer, S.; Jetter, R.; Kunst, L.; Wu, X.; Yephremov, A.; Samuels, L. Characterization of Arabidopsis ABCG11/WBC11, an ATP binding cassette (ABC) transporter that is required for cuticular lipid secretion. Plant J. 2007, 52, 485-498.

39. Panikashvili, D.; Savaldi-Goldstein, S.; Mandel, T.; Yifhar, T.; Franke, R.B.; Hofer, R.; Schreiber, L.; Chory, J.; Aharoni, A. The Arabidopsis DESPERADO/AtWBC11 transporter is required for cutin and wax secretion. Plant Physiol. 2007, 145, 1345-1360.

40. Pighin, J.A.; Zheng, H.; Balakshin, L.J.; Goodman, I.P.; Western, T.L.; Jetter, R.; Kunst, L.; Samuels, A.L. Plant cuticular lipid export requires an ABC transporter. Science 2004, 306, 702-704.

41. Luo, B.; Xue, X.Y.; Hu, W.L.; Wang, L.J.; Chen, X.Y. An ABC transporter gene of Arabidopsis thaliana, AtWBC11, is involved in cuticle development and prevention of organ fusion. Plant Cell Physiol. 2007, 48, 1790-1802.

42. Ukitsu, H.; Kuromori, T.; Toyooka, K.; Goto, Y.; Matsuoka, K.; Sakuradani, E.; Shimizu, S.; Kamiya, A.; Imura, Y.; Yuguchi, M.; et al. Cytological and biochemical analysis of COF1, an Arabidopsis mutant of an ABC transporter gene. Plant Cell Physiol. 2007, 48, 1524-1533. 
43. Oyama, T.; Shimura, Y.; Okada, K. The Arabidopsis HY5 gene encodes a bZIP protein that regulates stimulus-induced development of root and hypocotyl. Genes Dev. 1997, 11, 2983-2995.

44. The SIGnAL Website. Available online: http://signal.salk.edu (accessed on 19 July 2014).

45. The Arabidopsis Biological Resource Center. Available online: http://abrc.osu.edu (accessed on 19 July 2014).

46. The Arabidopsis Information Resource. Available online: https//www.arabidopsis.org (accessed on 19 July 2014).

(C) 2014 by the authors; licensee MDPI, Basel, Switzerland. This article is an open access article distributed under the terms and conditions of the Creative Commons Attribution license (http://creativecommons.org/licenses/by/3.0/). 